\title{
The Outcome of Unilateral Cochlear Implantation in Adults: Speech Recognition, Health-Related Quality of Life and Level of Anxiety and Depression: a One- and Three-Year Follow-Up Study
}

\author{
Pia Bergman 1,2,30 Björn Lyxell ${ }^{4,5}$ Henrik Harder ${ }^{3}$ \\ ${ }^{1}$ Department of Otorhinolaryngology, Jönköping County hospital, \\ Jönköping, Sweden \\ 2 Division of Neuro and Inflammation Science, Department of Clinical and \\ Experimental Medicine, Linköping University, Linköping, Sweden \\ ${ }^{3}$ Department of Otorhinolaryngology in Linköping, Anaesthetics, Operations \\ and Specialty Surgery Center, Region Östergötland, Linköping, Sweden \\ ${ }^{4}$ Department of Special Needs Education, Oslo University, Oslo, Norway \\ ${ }^{5}$ Linnaeus Centre HEAD, Swedish Institute for Disability Research, \\ Linköping University, Linköping, Sweden \\ ${ }^{6}$ Faculty of Medicine and Health, Örebro University, Örebro, Sweden
}

Address for correspondence Pia Bergman, MD, Department of Otorhinolaryngology, Linköping University Hospital, Länssjukhuset Ryhov, Jönköping, 55185, Sweden (e-mail: piab77@gmail.com).

Int Arch Otorhinolaryngol 2020;24(3):e338-e346.

\author{
Abstract \\ Keywords \\ - health-related quality \\ of life \\ - cognition \\ - cochlear implantation \\ - anxiety \\ - depression
}

Introduction Hearing impairment is a common disease worldwide, with a comprehensive impact, and cochlear implantation $(\mathrm{Cl})$ is an intervention for profound hearing impairment. Objective To study the outcome one and three years after unilateral $\mathrm{Cl}$ on hearing, health-related quality of life and level of depression and anxiety, and the correlation between the outcomes. Second, to study whether age, gender, etiology, operated side, residual hearing or cognitive performance can predict the outcome.

Methods A prospective longitudinal study including adults with profound postlingual hearing impairment, with respect to hearing (speech recognition), health-related quality of life (Health Utilities Index 3 ) and level of depression and anxiety (Hospital Anxiety and Depression scale), pre- $\mathrm{Cl}$, and one and three years post- $\mathrm{Cl}$. The total sample was composed of 40 participants ( $40 \%$ of men), with a mean age of 71 years. Results Speech recognition and the overall health-related quality of life improved one year post-CI $(p=0.000)$, without correlation ( $p=0.27)$, and with no difference three years post- $\mathrm{Cl}$. The hearing attribute (in the health-related quality of life instrument) improved one and three years post- $\mathrm{Cl}(p=0.000)$. The level of anxiety did not change one and three years post- $\mathrm{Cl}$. The level of depression improved one year post- $\mathrm{Cl}(p=0.036)$, and deteriorated three years post- $\mathrm{Cl}(p=0.031)$. Age, etiology, operated side, residual hearing and cognitive performance did not predict the outcome, but the female gender did significantly improve speech recognition compared with men $(p=0.009)$.

Conclusion The $\mathrm{Cl}$ significantly improved speech recognition, health-related quality of life and level of depression one year post- $\mathrm{Cl}$ without mutual correlation, and women performed significantly better than men. There were no further improvements three years post- $\mathrm{Cl}$, apart from the hearing attribute. received

March 27, 2019

accepted

September 24, 2019

published online

December 13, 2019
DOI https://doi.org/

$10.1055 / \mathrm{s}-0039-3399540$.

ISSN $1809-9777$.
Copyright $\odot 2020$ by Thieme Revinter

Publicações Ltda, Rio de Janeiro, Brazil

License terms

(c) $9 \triangleq \$$ 


\section{Introduction}

Hearing impairment (HI) is the 4th most common chronic disease worldwide; ${ }^{1}$ it affects 1.2 billion people, and this rate is steadily increasing. The prevalence of severe to profound $\mathrm{HI}$ (pure tone average [PTA] at $0.5-4 \mathrm{kHz} \geq 70 \mathrm{~dB}$ in the best ear or a speech recognition [SR] score $\leq 30 \%$ ) is of $0.2 \%$ in the Swedish adult population, which is of $\sim 22,000$ individuals. $^{2}$ One of the main impacts of $\mathrm{HI}$ is the decreased ability to communicate. Hearing impairment has a negative influence on health-related quality of life (HRQoL), ${ }^{3,4}$ and the severity of the hearing loss correlates with the reduction in HRQoL. ${ }^{3}$ It has become more and more common to measure the impact of health interventions in terms of HRQoL, including an evaluation of the outcome of the cochlear implantation (CI), and there are several definitions of HRQoL, as well as several different methods to measure it.

Hearing impairment is significantly associated with depression, especially among women. ${ }^{5}$ In a recent study, ${ }^{6}$ anxiety and depression were found to be more common and more severe in individuals with severe to profound $\mathrm{HI}$ (PTA $>70 \mathrm{~dB}$ in the better ear at $0.5 \mathrm{kHz}, 1 \mathrm{kHz}, 2 \mathrm{kHz}$ and $4 \mathrm{kHz}$ ) than in the general population. ${ }^{6}$ Hearing-impaired older adults have a higher incidence of hospitalization than those with normal hearing, ${ }^{7}$ and $\mathrm{HI}$ has also been shown to be a risk factor for mortality. 7,8

Cochlear implantation is a safe and effective intervention for severe to profound $\mathrm{HI}$ in adults. ${ }^{9}$ The general indication for $\mathrm{CI}$ is an inability to communicate using spoken language despite having optimally-programmed hearing aids (HAs). There are no definitive criteria for $\mathrm{CI}$, but the current benchmark is PTA $(0.5 \mathrm{kHz}, 1 \mathrm{kHz}, 2 \mathrm{kHz}, 4 \mathrm{kHz}) \geq 70 \mathrm{~dB} \mathrm{HL}$ and $\mathrm{SR} \leq 50 \%$ correct repeated words in the better ear with HAs; the criteria can be more lenient in case of rapid progression. $^{10}$

Several studies show a significant improvement in SR after $\mathrm{CI}^{11-13}$ as well as a significant improvement in HRQoL, measured in different ways: SF-36 (The Short Form 36 questions), ${ }^{11-13}$ NCIQ (Nijmegen Cochlear Implant Questionnaire), ${ }^{11,14,15}$ GBI (Glasgow Benefit Inventory) ${ }^{15,16}$ and Health Utilities Index 2 and 3 HUI2-3 (Health Utilities Index 2-3) ${ }^{12,13}$. Based on the register data, one study ${ }^{6}$ found a lower risk of negative impact on HRQoL among $\mathrm{CI}$ users compared with individuals with severe to profound $\mathrm{HI}$ without $\mathrm{CI}$.

Hirschfelder et $\mathrm{al}^{17}$ have shown a correlation between SR and HRQOL (using the NCIQ and SF-36) in adults with severe HI who were submitted to $\mathrm{CI}$, but other studies have failed to replicate this result (using the NCIQ and SSQ [Speech, Spatial and Qualities] ${ }^{12}$ and the NCIQ GBI and HUI3 questionnaires ${ }^{15}$ ). A meta-analysis ${ }^{18}$ of 14 articles, involving a total of $679 \mathrm{CI}$ patients, resulted in a low correlation between patientreported outcome measures, including HRQoL and SR, which, according to the authors, supports the need for a more regular use of HRQoL instruments to assess CI outcomes. ${ }^{18}$

There are several publications reporting the long-term outcome of SR and HRQoL among adult CI users. No significant growth or decline in speech perception is observed after 6-24 months post-CI. ${ }^{19,20}$ When investigating the elderly group of CI users ( $\geq 70$ years), the same stable results regarding SR and HRQOL are shown. ${ }^{21,22}$

Previous results suggest different predictive factors for post-CI performance, such as age, ${ }^{23,24}$ gender, ${ }^{25}$ duration of deafness, ${ }^{26}$ residual hearing, ${ }^{27}$ cognitive parameters, ${ }^{23}$ eti$\operatorname{ology}^{24}$ and psychosocial factors. ${ }^{28}$

\section{Objective}

The first aim of the present study was to examine the outcomes one and three years after $\mathrm{CI}$ in adults with bilateral severe to profound postlingual $\mathrm{HI}$ with respect to hearing, HRQoL, level of depression and anxiety, and to determine the correlation between the outcomes.

The second aim was to investigate whether age, gender, etiology, side of implantation, residual hearing, level of anxiety and depression and cognitive performance could predict the outcome.

\section{Subjects and Methods}

\section{Subjects}

Participants were recruited from the cochlear implant programme at the Department of Otolaryngology, Linköping, a tertiary teaching university hospital in Sweden, from 1 April 2011 to 31 May 2013. Eligibility for the study was defined as: 1) age $\geq 18$ years at the time of the $\mathrm{CI} ; 2$ ) a bilateral severe to profound postlingual HI defined according to PTA and/or SR; 3 ) unilateral $\mathrm{CI}$; and 4 ) at least three years of experience with $\mathrm{CI}$.

Out of a total of 60 implanted individuals, 1 died before the 1-year follow-up because of causes not related to the CI, 2 were not able to participate because of language, 1 was excluded because of a severe visual impairment (the subject could not fill out the questionnaires), 1 was excluded because of cognitive dysfunction to a degree that made it impossible to answer the questionnaires, and $3 \mathrm{CI}$ users did not want to answer any questionnaires. One $\mathrm{CI}$ user was reoperated, and did not answer the questionnaire. Thus, $51 \mathrm{CI}$ users were asked for informed consent to participate in the study, and 40 (78\%) accepted the invitation. A total of 16 (40\%) participants were men. The mean age at implantation was 71 years (standard deviation [SD]: 11.3 years), and the median of age was 72 years (range: $19-88$ years). Women were on average five years younger than men at the $\mathrm{CI}$ surgery. The majority $(n=33)$ of the subjects were retired; 1 participant classified him/herself as active, and 6 participants left the question about employment unanswered. The right side was implanted in 23 participants and the left side, in 17.

The etiologies reported are based on the clinical evaluation before implantation, and one participant could have more than one etiology for $\mathrm{CI}$ candidacy. Etiology (number denoted): hereditary (12), noise-induced (8), unknown (6), auditory neuropathy (4), Ménière disease (2), otitis media (2), parotitis (2), meningitis (1), rubella (1), sudden deafness (2), vestibular schwannoma (1) (the CI was implanted in the opposite ear), branchio-oto-renal syndrome (BOR) (1), probably autoimmune base (1), Usher 2 (1), and peripheral polyneuropathy (1). In addition to these etiologies, presbyacusis may have had an impact. 


\section{Methods}

The study design was prospective and longitudinal. The participants were followed for 3 years. Approval from the regional ethical review board at Linköping University was obtained (Number/ID:2011/87-31). Written informed consent was received from all 40 participants.

\section{Review of Medical Records}

Information about age at surgery, gender, etiology, side of implantation, audiological measurements (including air conduction thresholds and SR) and cognitive performance was collected from medical records.

In-quiet $\mathrm{x}$-ish speech audiometry (SR) is based on lists with 50 phonemically balanced monosyllabic words. ${ }^{29}$ It is a standardized and validated method with a variability of $\sim$ $10 \%$, and the result is scored in percentage of correct words repeated. The PTA was defined as the average of the air conduction pure-tone thresholds at $0.5 \mathrm{kHz}, 1 \mathrm{kHz}, 2 \mathrm{kHz}$, and $4 \mathrm{kHz}$; when the threshold exceeded the maximum output level of the audiometer, $130 \mathrm{~dB}$ were used. ${ }^{30}$

To measure the reality-based hearing function, that is, the SR that is nearest to each individual's hearing function in everyday life, we chose the best possible speech recognition (BPSR) that each participant could perform, which was based on the best SR score obtained at $65 \mathrm{~dB}$ hearing level in a sound field pre-CI and one and three years post-CI, unilaterally or bilaterally, with or without optimally-adjusted HA(s). To clarify, from the different measurements of SR, we chose each participant's highest SR, supposing that it corresponds best to their daily hearing situation. The BPSR pre-CI and one and three years post-CI, as well as the SR on the side to be submitted to $\mathrm{CI}$ and the side submitted to $\mathrm{CI}$ were analyzed.

\section{HUI3 and HADS Questionnaires}

In the present work, HRQoL is defined as the value assigned to one's duration of life as modified by the impairments, functional states, perceptions, and social opportunities that are influenced by disease, injury, treatment or policy. ${ }^{31}$ To asses HRQoL, the HUI3 questionnaire was used, and the Hospital Anxiety and Depression Scale (HADS) was used to assess the levels of depression (HAD-D) and anxiety (HAD-A). The questionnaires were sent by mail pre-CI and one and three years post-CI to all participants.

The HUI3 is a generic test, and it has been used in many different HRQoL studies, in which the objective is to monitor health changes due to treatment. It has strong theoretical foundations, is valid and reliable. ${ }^{32}$ It is a self-assessment questionnaire with 15 items corresponding to 8 dimensions (vision, hearing, speech, ambulation, dexterity, emotion, cognition and pain). The HUI3 attribute levels are determined based on responses to one or more questions, and they represent functional classes. Single-attribute utility functions describe the burden of morbidity for a person, attribute by attribute. The HUI3 provides both single-attribute and overall utility functions in a scale in which dead $=0.00$ and perfect health $=1.00 .^{32}$

The HADS is a brief, self-assessment mood scale with 14 items, with scores that range from 0 to 21 for either anxiety or depression, and a cut-off point $\geq 8$. The subscale scores (HAD-A and HAD-D) can be used to measure the severity, and their repeated application will provide information on changes. ${ }^{33,34}$ The HADS is reliable and its validity is good, and results based on the instrument show a high correlation with other instruments that measure psychological illness. ${ }^{35}$

\section{Cognitive Tests}

The cognitive capacity was assessed by means of five different tests, each one assessing some specific cognitive ability, and they were applied pre-CI by means of a computer. The reading span test was used as a measure of working memory capacity. The task was to decide whether the sentences were semantically absurd or not, and after reading them, recall either the first or the final words of the sentences in correct serial order. The physical matching task was used to assess the participant's general reaction time and to determine whether two simultaneously presented letters had the same physical shape. The lexical decision-making test was used to measure the lexical access speed. The task was to decide whether a combination of three letters constituted a real word or not. The rhyme-judgment test was used to measure the phonologic ability. The task was to decide whether two words presented simultaneously rhymed or not. A test of antonyms was used to assess one aspect of the participant's verbal ability. The test used is part of the Wechsler Adult Intelligence Scale (WAIS) battery, and is one of the most frequently used tests of intelligence. The results were calculated in terms of percentage of correct responses and the time required to perform the task.

In addition, in the HUI3 there is a dimension of cognition, (HUI3 CU), which measures one aspect of long-term memory.

\section{Data Analysis}

The results of the audiological measurements, HUI3 and HADS pre-CI and one and three years post-CI were analyzed. Consequently, every $\mathrm{CI}$ recipient was his or her own control. The statistical calculations were performed with the International business Machines Statistical Package for the Social Sciences (IBM SPSS, IBM Corp., Armonk, NY, US) software, version 23. When investigating the occurrence of significance, a nonparametric test, the Wilcoxon test (matched-pair signed rank), was used due to the heterogeneous group of variables with both ordinal and interval data. The significance level was set at $p<0.05$. The SR and HUI3 scores were treated as interval data and the HUI3 levels and the sum of the HADS scores, as ordinal data. The Spearman test was used when analyzing correlation; in Spearman rho $(\rho)$ correlation coefficient, $\rho>0.6$ was chosen as a high correlation.

\section{Results}

\section{Audiometric Tests}

The pre-CI assessment of residual hearing showed a large variation due to the variation in hearing ability. Pre-CI, the mean PTA was of $88 \mathrm{~dB}$ (SD: 16.2; range: 55-130 dB) on the best side, and of $100 \mathrm{~dB}$ (SD: 17.5 ; range: $60-130 \mathrm{~dB}$ ) on the side to receive the implant. For men, the pre-CI PTA 


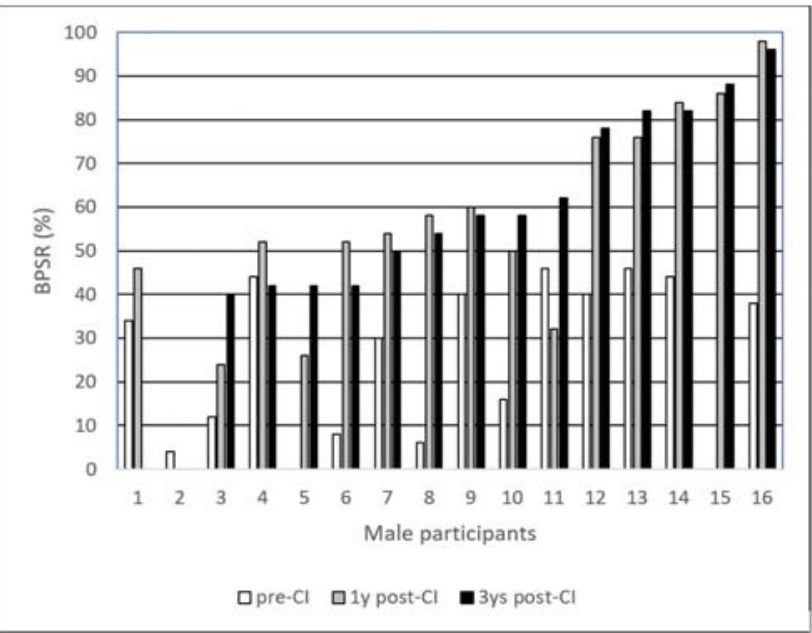

Fig. 1 Best possible speech recognition (BPSR) pre- and one and three years post-cochlear implantation $(\mathrm{Cl})$ in the male subgroup.

was of $96 \mathrm{~dB}$ (SD: 11.4) on the side to receive the implant; for women, it was of $102 \mathrm{~dB}$ (SD: 20.5). Only 10 out of 40 participants could produce a result on the speech audiometric test on the side to receive the implant without HA, but 18 participants could produce a result with an optimally adjusted HA. Pre-CI, the mean SR was of $7.9 \%$ (SD: 10.6\%; range: $0-34.0 \%$ ) with $\mathrm{HA}$ on the side to receive the implant, and the mean BPSR was of $23.8 \%$ (SD: $18.0 \%$; range: $0-58.0 \%$ ).

One-year post-CI, on the CI side, the mean SR was of $54.7 \%$ (SD: 24.3\%; range: 0-98.0\%), showing a significant improvement of $46.8 \%$ (SD: $24.3 ; p<0.000$ ) but without a significant difference 3 years post-CI: $54.3 \%$ (SD: $21.4 \%$; range: $0-98.0 \%$ ). The mean BPSR one year post-CI was of $62.8 \%$ (SD: 21.5 ; range: $0-98.0 \% ; p<0.001$ ), with no significant difference 3 years post-CI: 59.6\% (SD: $21.7 \%$; range: $0-96.0 \% ; n=38$ ). The BPSR one and three years post-CI were correlated $(\rho=0.87)$.

A reduction greater than $10 \%$, that is, 5 words, in the BPSR, was observed in 1 patient 1 year post-CI compared with the pre-CI period, and reductions greater than $10 \%$ were observed in 8 patients 3 years post- $\mathrm{Cl}$ compared with 1 year post-CI, but no explanations for this were identified. No significant correlation was found between the residual hearing (BPSR) pre-CI and the hearing outcome (BPSR) one $(\rho=0.34)$ and three $(\rho=0.30)$ years post-CI.

The BPSR for the gender subgroups pre- $\mathrm{Cl}$ and one and three years post-CI can be seen in - Figs. 1 and $\mathbf{2}$. At the follow up after three years, there was missing data on two individuals in the male group, and no missing data in the female group, but $\mathrm{BPSR}=0$ for two individuals. No significant gender difference in BPSR was found pre-CI, but women improved significantly $(p=0.009)$ more than men 1 year post-CI, on average $16.8 \%$ better, as shown in - Table 1 . Similar results were observed when evaluating the SR only on the side to receive the implant or on the implanted side: women improved significantly $(p=0.036)$ more than men one year post- $\mathrm{CI}$. By the 3 years post-CI follow up, the men's mean BPSR was of $54.6 \%$ (SD: $27.8 \%$; range: $0-96.0 \% ; n=14$ ) and the women's was of $63.1 \%$ (SD: $15.7 \%$; range: $24.0-88.0 \%$; $n=24)$, which is not a significant $(p=1.53)$ gender difference, since the men's score remained unchanged while that of the women decreased by $5.1 \%$.

The results of the BPSR and SR one and three years after the procedure on the side that received the $\mathrm{Cl}$, as well as the differences in the results between the two periods were analyzed in subgroups by age (separated by the median age of 72), and no significant differences were found. Moreover, when excluding the outliers (one participant was much younger than the rest), the result remained the same (data not shown).

The results of hearing (BPSR pre- $\mathrm{Cl}$ and one year post- $\mathrm{Cl}$ ) were also analyzed after transforming the data in "rationalized" arcsine units (RAUs), ${ }^{36}$ but no significant correlations emerged. The RAUS statistical method is used in analyses related to scales, such as SR scores, in which a change is not comparable in both ends of the scale: the experienced change from SR $60 \%$ to $70 \%$ is not the same as from $15 \%$ to $25 \%$, for example.

The use of HAs on the contralateral side could be noted 1 year post-CI among 30 of the 40 participants, 5 subjects did

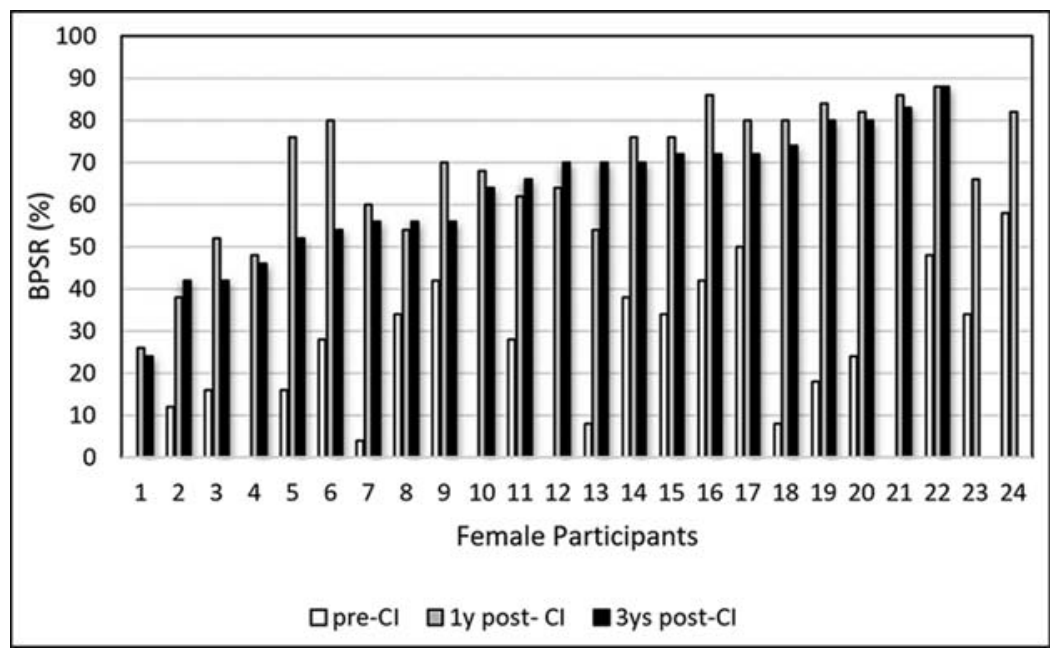

Fig. 2 Best Possible Speech Recognition (BPSR) pre- and one and three years post-Cl in the female subgroup. 
Table 1 Outcomes of BPSR, SR on the CI side, HUI3 HU and HUI3 OU separated by gender pre- and one and three years post-CI mean (SD)

\begin{tabular}{|l|l|l|l|l|l|l|}
\hline Outcome & \multicolumn{2}{|l|}{ Men } & Women & \multicolumn{2}{l|}{} \\
\hline & Pre-CI & $\begin{array}{l}\text { One year } \\
\text { post-Cl }\end{array}$ & $\begin{array}{l}\text { Three years } \\
\text { post-Cl }\end{array}$ & $\begin{array}{l}\text { Pre-Cl } \\
\text { post-Cl }\end{array}$ & $\begin{array}{l}\text { Three years } \\
\text { post-Cl }\end{array}$ \\
\hline BPSR (\%) & $\begin{array}{l}25.5(18.1) \\
(n=16)\end{array}$ & $\begin{array}{l}54.6(25.9) \\
(n=16)\end{array}$ & $\begin{array}{l}54.6(27.8) \\
(n=16)\end{array}$ & $22.6(18.2)(n=24)$ & $\begin{array}{l}68.3(16.4) \\
(n=24)\end{array}$ & $\begin{array}{l}63.1(15.7) \\
(n=22)\end{array}$ \\
\hline SR on the CI side (\%) & $\begin{array}{l}8.1(11.3) \\
(n=16)\end{array}$ & $\begin{array}{l}44.4(29.6) \\
(n=16)\end{array}$ & $\begin{array}{l}48.7(27.2) \\
(n=14)\end{array}$ & $\begin{array}{l}7.7(10.4) \\
(n=24)\end{array}$ & $\begin{array}{l}61.3(17.8) \\
(n=22)\end{array}$ & $\begin{array}{l}57.9(16.6) \\
(n=22)\end{array}$ \\
\hline HUI3 HU & $\begin{array}{l}0.29(0.25) \\
(n=16)\end{array}$ & $\begin{array}{l}0.66(0.18) \\
(n=16)\end{array}$ & $\begin{array}{l}0.85(0.10) \\
(n=15)\end{array}$ & $\begin{array}{l}0.29(0.31) \\
(n=23)\end{array}$ & $0.62(0.23)(n=22)$ & $\begin{array}{l}0.87(0.80) \\
(n=18)\end{array}$ \\
\hline HUI3 OU & $\begin{array}{l}0.48(0.20) \\
(n=16)\end{array}$ & $\begin{array}{l}0.69(0.16) \\
(n=16)\end{array}$ & $\begin{array}{l}0.63(0.24) \\
(n=15)\end{array}$ & $\begin{array}{l}0.43(0.24) \\
(n=22)\end{array}$ & $\begin{array}{l}0.63(0.20) \\
(n=22)\end{array}$ & $\begin{array}{l}0.59(0.18) \\
(n=17)\end{array}$ \\
\hline
\end{tabular}

Abbreviations: BPSR, best possible speech recognition; $\mathrm{Cl}$, cochlear implantation; HUI3 HU, Health Utilities Index 3, hearing utility; HUI3 OU, Health Utilities Index 3, overall utility; SD, standard deviation; SR, speech recognition.

not use HA, 1 meant to try an HA, and data were missing in 3 cases. One participant was submitted to a second $\mathrm{CI}$ after being included in the study. Three years post-CI, 25 participants used HAs on the contralateral side, 1 used a vibrant soundbridge, 3 did not use HAs, and data were missing in 11 cases (2 participants moved).

\section{HRQoL}

Pre- and one-year post-CI, 38 participants completed the HUI3 questionnaires sufficiently to enable the calculation of the overall utility multi-attribute score (HUI3 OU). Three years post-CI, 32 participants completed the questionnaires.

The HUI3 Hearing level (HUI3 HL) 6, "Unable to hear at all," was the most common level pre-CI. One and three years postCI, HUI3 HL 3 was the most common ("Able to hear what is said in a conversation with one other person in a quiet room with a hearing aid" and "Able to hear what is said in a group conversation with at least three other people, with a hearing aid").

According to the classification system to categorize HUI3 attribute levels by disability (none, mild, moderate and severe), $67.5 \%$ of the participants were classified as severe, and $30 \%$, as moderate pre-CI, while only $17.5 \%$ were classified as severe, and $72.5 \%$, as moderate 1 year post- $\mathrm{CI}$; 3 years postCI, only $10 \%$ were classified as severe, and $70 \%$, as moderate.

The single-attribute utility score of hearing (HUI3 HU) significantly improved one year post-CI, as well as the utility scores of emotion and pain, and the multi-attribute overall utility score, (HUI3 OU; see - Table 2). The HUI3 HU significantly improved again between one and three years post-CI.

A high correlation was observed between the HUI3 HU and HUI3 OU pre-CI $(\rho=0.76)$; however, this was not repeated one and three years post-CI. A correlation could also be observed between the HUI3 OU pre-CI and 3 years post- $\mathrm{Cl}(\rho=0.58)$, and 1 and 3 years post- $\mathrm{CI}(\rho=0.62)$, that is, the degree of HRQoL pre-CI correlates with the degree of HRQoL post-CI.

No significant gender differences were observed in the HUI3 HU pre-, one and three years post-CI, but it is worth mentioning that men scored higher one year post-CI, and women scored higher three years post-CI.

\section{Levels of Anxiety and Depression}

All 40 participants filled out the HADS pre- and one year post-CI; however by the 3 years of follow-up only 31 participants had filled out the HAD-A, and 30 had filled out the HAD-D. The overall results are shown in - Fig. 3. The most frequent score on the HAD-A and HAD-D pre-, one and three years post-CI was zero. The scores on the HAD-A did not significantly change pre-, one $(p=0.260)$ and three years $(p=0.914)$ post-CI. The HAD-D significantly improved one year post-CI $(p=0.036)$, and significantly deteriorated three years post-CI $(p=0.031)$, so there was no significant difference between scores on the HAD-D pre- and three years post-

Table 2 Mean single- and multi-attribute-scores of the HUI3 pre- and one and three years post- $\mathrm{Cl}$

\begin{tabular}{|l|l|l|l|}
\hline HUI3 & Pre-Cl & $\begin{array}{l}\text { One year } \\
\text { post-CI }\end{array}$ & $\begin{array}{l}\text { Three years } \\
\text { post-Cl }\end{array}$ \\
\hline Vision, HUI3 VU & $\begin{array}{l}0.88 \\
(n=39)\end{array}$ & $\begin{array}{l}0.89 \\
(n=40)\end{array}$ & $\begin{array}{l}0.97^{* *} \\
(n=32)\end{array}$ \\
\hline Hearing, HUI3 HU & $\begin{array}{l}0.29 \\
(n=39)\end{array}$ & $\begin{array}{l}0.63^{*} \\
(n=38)\end{array}$ & $\begin{array}{l}0.86^{* *} \\
(n=33)\end{array}$ \\
\hline Speech, HUI3 SU & $\begin{array}{l}0.97 \\
(n=39)\end{array}$ & $\begin{array}{l}0.98 \\
(n=38)\end{array}$ & $\begin{array}{l}0.99 \\
(n=33)\end{array}$ \\
\hline Ambulation, HUI3 AU & $\begin{array}{l}0.96 \\
(n=40)\end{array}$ & $\begin{array}{l}0.96 \\
(n=40)\end{array}$ & $\begin{array}{l}0.96 \\
(n=33)\end{array}$ \\
\hline Dexterity, HUI3 DU & $\begin{array}{l}0.97 \\
(n=40)\end{array}$ & $\begin{array}{l}0.97 \\
(n=40)\end{array}$ & $\begin{array}{l}0.98 \\
(n=33)\end{array}$ \\
\hline Emotion, HUI3 EU & $\begin{array}{l}0.88 \\
(n=40)\end{array}$ & $\begin{array}{l}0.95^{*} \\
(n=40)\end{array}$ & $\begin{array}{l}0.96 \\
(n=33)\end{array}$ \\
\hline Cognition, HUI3 CU & $\begin{array}{l}0.98 \\
(n=40)\end{array}$ & $\begin{array}{l}0.99 \\
(n=40)\end{array}$ & $\begin{array}{l}0.99 \\
(n=33)\end{array}$ \\
\hline Pain, HUI3 PU & $\begin{array}{l}0.90 \\
(n=39)\end{array}$ & $\begin{array}{l}0.94^{*} \\
(n=40)\end{array}$ & $\begin{array}{l}0.96 \\
(n=33)\end{array}$ \\
\hline Overall, HUI3 OU & $\begin{array}{l}0.45 \\
(n=38)\end{array}$ & $\begin{array}{l}0.66^{*} \\
(n=38)\end{array}$ & $\begin{array}{l}0.61 \\
(n=32)\end{array}$ \\
\hline
\end{tabular}

Abbreviations: $\mathrm{Cl}$, cochlear implantation; HUI3, Health Utilities Index 3. Notes: *Significant difference between pre- $\mathrm{Cl}$ and one year post- $\mathrm{Cl}$ scores, $p<0.05$. ${ }^{* *}$ Significant difference between one and three years post-Cl scores, $p<0.05$. 


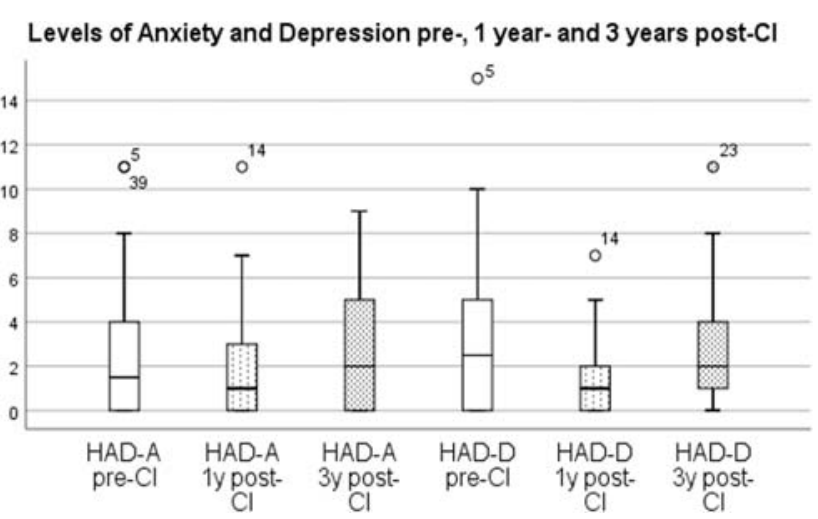

Fig. 3 Boxplot showing the Hospital Anxiety and Depression Scale (HADS) anxiety (HAD-A) and depression (HAD-D) subscales pre- and one and three years post- $\mathrm{Cl}$.

$\mathrm{CI}(p=0.762)$. Every participant $(n=5)$ with a subscale score $\geq 8$ pre-CI had the score normalized 1 year post-CI, but 2 participants had a subscale score $\geq 8$ on the HAD-A 1 year post-CI, and another 2 participants had a subscale score $\geq 8$ on the HAD-A 3 years post-CI. In general women scored higher (but not significantly) on the HAD-A and HAD-D than men pre- and 1 year post-CI. By the three years of follow-up, women scored higher on the HAD-A subscale and men, on the HAD-D subscale. A high correlation could be observed between the HAD-A and HAD-D scores pre-CI $(\rho=0.67)$ and one year $(\rho=0.63)$ and three years post-CI $(\rho=0.75)$.

\section{Cognition}

One participant was investigated very rapidly, due to an acute infektion, and therefore did not perform the cognitive test battery, nor did 2 participants with severe vision impairment, resulting in a sample composed of 37 participants. The results were presented in percentage of correct responses and the time it took to generate a response.

There was no correlation between the cognitive dimension (HUI3 CU) pre-CI and one $(\rho=0.19)$ and three-years $(\rho=0.37)$ post- $\mathrm{CI}$, but the scores for this dimension one and three years post-CI were correlated $(\rho=0.82)$.

None of the results of the cognitive subtests in the WAIS battery correlated with the HUI3 CU pre-, one, and three years
post-CI. The results of the cognitive performance were further analyzed in subgroups of gender and age (median age: 72 years), and they had the same performance ( - Table 3 ). None of the results of the cognitive subtests in the WAIS battery correlated with the HUI3 CU pre-, one, and three years post-CI ( Table 4 ).

\section{Correlations Between the Outcomes}

There was no correlation between the SR, HUI3 and HADS, including measurements taken pre- and one and three-years post-CI (the SR evaluated was as BPSR and as SR only on the $\mathrm{CI}$-side and considering the maximum score as well as the gain, that is, the difference between the BPSR one year postand pre-CI). In other words, the pre-CI scores of the SR, HUI3 HAD-A and HAD-D could not predict the post-CI outcomes of the same variables after examining the total group as well as the gender and age subgroups.

A subgroup analysis of the high performers by the oneyear follow-up, that is, the best quartile (BPSR $\geq 82 \%, n=9$ [3 men and 6 women]) revealed a high and reverse correlation between the BPSR pre-CI and the HUI3 OU one year post$\mathrm{CI}(\rho=-0.68)$. An analysis of the participants with the largest reduction in BPSR three years post-CI showed a higher mean HUI3 HU than the total (data not shown).

No correlation was found between the HADS and HUI3, preand one year post-CI, but three years post-CI, there was a negative correlation between the HUI3 OU and the HAD-D ( $\rho=$ $-0.81)$ and the HAD-A $(\rho=-0.61)$. Another negative correlation was found between the HAD-D pre-CI and the HUI3 OU three years post- $\mathrm{CI}(\rho=-0.61)$. No correlation was found between the cognitive performance pre-CI and gender, age at surgery, HADS, HUI3 (HU and OU) pre-, one and three years post-CI.

\section{Analyses of Background Factors}

No correlation was found between age at surgery, etiology, side of implantation, residual hearing, cognitive performance and the CI outcomes of hearing (SR), HRQoL (HUI3 $\mathrm{OU})$ and the levels of anxiety and depression on the HADS. The low correlation between the cognitive performance and pre- and one and three years post-CI outcome is shown in -Table 3. As mentioned before, women improved significantly more than men in SR one year post-CI.

Table 3 Mean (SD) performance for the total group and the subgroups separated by gender and age pre-Cl

\begin{tabular}{|l|l|l|l|l|l|}
\hline Cognitive Performance & Total & Men & Women & Age $\leq 72$ & Age $>72$ \\
\hline $\begin{array}{l}\text { Reading span } \\
\text { (\% of right answers) }\end{array}$ & $\begin{array}{l}47.3(10.7) \\
(n=36)\end{array}$ & $\begin{array}{l}45.8(12.0) \\
(n=14)\end{array}$ & $\begin{array}{l}48.3(10.0) \\
(n=22)\end{array}$ & $\begin{array}{l}47.0(11.6) \\
(n=18)\end{array}$ & $\begin{array}{l}47.7(10.1) \\
(n=18)\end{array}$ \\
\hline $\begin{array}{l}\text { Physical matching } \\
\text { (\% of right answers) }\end{array}$ & $\begin{array}{l}85.9(16.4) \\
(n=37)\end{array}$ & $\begin{array}{l}85.9(17.7) \\
(n=15)\end{array}$ & $\begin{array}{l}85.9(15.9) \\
(n=22)\end{array}$ & $\begin{array}{l}88.7(12.4) \\
(n=18)\end{array}$ & $\begin{array}{l}83.3(19.4) \\
(n=19)\end{array}$ \\
\hline $\begin{array}{l}\text { Lexical decision-making } \\
\text { (\% of right answers) }\end{array}$ & $\begin{array}{l}95.7(5.1) \\
(n=37)\end{array}$ & $\begin{array}{l}95.6(5.6) \\
(n=15)\end{array}$ & $\begin{array}{l}95.7(4.9) \\
(n=22)\end{array}$ & $\begin{array}{l}95.9(5.1) \\
(n=18)\end{array}$ & $\begin{array}{l}95.5(5.3) \\
(n=19)\end{array}$ \\
\hline $\begin{array}{l}\text { Rhyme judgment } \\
\text { (\% of right answers) }\end{array}$ & $\begin{array}{l}77.0(15.9) \\
(n=37)\end{array}$ & $\begin{array}{l}70.9(15.9) \\
(n=15)\end{array}$ & $\begin{array}{l}81.1(14.8) \\
(n=22)\end{array}$ & $\begin{array}{l}75.9(15.8) \\
(n=18)\end{array}$ & $\begin{array}{l}78.0(16.3) \\
(n=19)\end{array}$ \\
\hline $\begin{array}{l}\text { Antonyms } \\
\text { (numbers right) }\end{array}$ & $\begin{array}{l}13.4(4.9) \\
(n=36)\end{array}$ & $\begin{array}{l}13.5(5.3) \\
(n=14)\end{array}$ & $\begin{array}{l}13.4(4.8) \\
(n=22)\end{array}$ & $\begin{array}{l}13.8(5.1) \\
(n=18)\end{array}$ & $\begin{array}{l}13.0(4.9) \\
(n=18)\end{array}$ \\
\hline
\end{tabular}

Abbreviations: $\mathrm{Cl}$, cochlear implantation; HUI3, Health Utilities Index 3; SD, standard deviation. 
Table 4 Correlation between cognitive performance and pre-, one- and three years post-Cl outcome

\begin{tabular}{|c|c|c|c|c|c|c|c|c|c|c|c|c|}
\hline \multirow[t]{2}{*}{ Cognitive subtest } & \multicolumn{3}{|l|}{ BPSR } & \multicolumn{3}{|c|}{ HUI3 HU } & \multicolumn{3}{|c|}{ HUI3 CU } & \multicolumn{3}{|c|}{ HUI3 OU } \\
\hline & Pre-Cl & $\begin{array}{l}\text { One } \\
\text { year } \\
\text { post-Cl }\end{array}$ & $\begin{array}{l}\text { Three } \\
\text { years } \\
\text { post-Cl }\end{array}$ & Pre-Cl & $\begin{array}{l}\text { One } \\
\text { year } \\
\text { post-Cl }\end{array}$ & $\begin{array}{l}\text { Three } \\
\text { years } \\
\text { post-Cl }\end{array}$ & Pre-Cl & $\begin{array}{l}\text { One } \\
\text { year } \\
\text { post-Cl }\end{array}$ & $\begin{array}{l}\text { Three } \\
\text { years } \\
\text { post-CI }\end{array}$ & Pre-Cl & $\begin{array}{l}\text { One } \\
\text { year } \\
\text { post-Cl }\end{array}$ & $\begin{array}{l}\text { Three } \\
\text { years } \\
\text { post-CI }\end{array}$ \\
\hline $\begin{array}{l}\text { Reading span } \\
\text { (\% of right answers) }\end{array}$ & 0.15 & 0.21 & 0.26 & 0.33 & -0.12 & -0.11 & 0.24 & -0.02 & 0.08 & 0.28 & 0.08 & 0.28 \\
\hline $\begin{array}{l}\text { Physical matching } \\
\text { (\% of right answers) }\end{array}$ & 0.03 & 0.30 & 0.31 & 0.08 & 0.08 & 0.01 & 0.02 & -0.03 & -0.09 & -0.06 & 0.10 & -0.08 \\
\hline $\begin{array}{l}\text { Lexical } \\
\text { decision-making } \\
\text { (\% of right answers) }\end{array}$ & 0.22 & 0.12 & 0.07 & 0.28 & -0.11 & -0.14 & -0.11 & -0.09 & 0.00 & 0.04 & -0.27 & -0.03 \\
\hline $\begin{array}{l}\text { Rhyme } \\
\text { judgment } \\
\text { (\% of right answers) }\end{array}$ & 0.24 & 0.21 & 0.12 & 0.27 & 0.20 & 0.14 & 0.07 & 0.18 & 0.27 & 0.08 & 0.18 & 0.16 \\
\hline $\begin{array}{l}\text { Antonyms } \\
\text { (\% of right answers) }\end{array}$ & 0.25 & 0.20 & 0.15 & 0.23 & 0.23 & 0.07 & 0.07 & 0.33 & 0.39 & 0.13 & 0.33 & 0.25 \\
\hline
\end{tabular}

Abbreviatons: BPSR, best possible speech recognition; Cl, cochlear implantation; CU, Cognition Utility; HU, Hearing Utility; HUI3, Health Utilities Index 3; OU, Overall Utility.

Note: Spearman's rho $(\rho)$ correlation coefficient. No high correlations were observed.

\section{Discussion}

The results of this one- and three-year follow-up study show that $\mathrm{CI}$ improves hearing (SR) and HRQoL (HUI3), a finding that is in line with that of several previous studies. ${ }^{11,14,15}$ Furthermore, the results show no correlation between the level of hearing and the level of HRQoL pre- and post-CI. Neither did it matter whether the absolute number of percentage points of improvement in SR or the gain was used. Thus, the improvement in hearing does not necessarily follow the degree of improvement in HRQoL. This is an interesting finding, as one would expect HRQoL to be better with better hearing. One possible explanation is that the outcome of the $\mathrm{CI}$ is more complex and multi-dimensional than the sheer improvement in SR. According to the current results, both hearing and HRQoL are important measures of the outcome of the CI. As improvements in implant technology and methods of surgery lead to the expansion of the indication criteria for $\mathrm{CI}$ (patients with more residual hearing are implanted), it is important to investigate not only the hearing outcomes, but also other factors, such as the HRQoL.

In previous studies, many different audiological methods and HRQoL instruments have been used, which could explain the contradicting findings regarding the question of whether post-CI results for hearing and HRQoL correlate or not. The method of testing SR could also play an important role. In the present study, a speech audiometric in-quiet test was used to measure the SR. The use of an in-noise speech test could probably describe the functionality better, but we don't have enough data for that analysis, because only a few participants could produce a result in the in-noise speech test.

Another issue related to methodology in the published studies is the fact that remarkably often the definition of QoL/HRQoL is missing, and it is thus unclear what is being measured. In the end, a conventional definition of QoL/ HRQoL applicable to hearing studies would be desirable.
It is generally difficult to compare the results obtained in different countries or language areas, as speech audiometry is dependent on the language used. Considering clinical studies, particularly those focused on individuals with severe to profound HI, there are participants who are not able to perform open-set speech audiometric tests due to the severity of their HI. This was the case in the present study. Because we aimed to measure which scenario was the closest to the subjects' real-life hearing capacity, we chose what we call BPSR. Instead of solely focusing on the improvement in hearing acuity on the operated $\mathrm{CI}$ side, the hearing outcome was based on the participants' best speech recognition scores, which we regard as an ecological situation.

The HUI3 has been recommended in several recent studies when measuring HRQoL in populations with hearing complaints, ${ }^{37,38}$ including CI users. $^{39}$ Differences $\geq 0.03$ in the mean HUI3 OU are clinically important. ${ }^{40}$ In the present study, the HUI3 OU difference 1 year post-CI was of 0.21 , which indicates a large-scale positive change. The same difference in previous studies was of $0.117,,^{41} 0.15^{42}$ and $0.17 .^{39}$ Interestingly, not only were the hearing single-attribute (HUI3 HU) and multi-attribute scores (HUI3 OU) significantly improved, but the single-attribute scores of pain (HUI3 PU) and emotion (HUI3 EU) were also improved, as previously described. ${ }^{11}$ Moreover, CI users score higher in HRQoL with respect to pain and emotion compared with people with normal hearing. ${ }^{43}$

Concerning the different hearing measurements, SR and HUI3 HU, both improved significantly one year post-CI, but without correlation. The SR remained unchanged three years post-CI, but the HUI3 HU significantly improved again. This may foment further discussion regarding how hearing/hearing residuals should be assessed in the CI-candidacy procedure, and how the hearing outcome should be evaluated. Similarly, one can discuss the different ways of assessing cognition, as the cognitive tests and the HUI3 CU did not correlate. 
No previously published study has focused on monitoring the $\mathrm{CI}$ procedure with the HADS instrument, as far as we know, and only a few studies on HI have used the HADS. ${ }^{6,44}$ In conclusion, the level of anxiety and depression is low in this group both before and after $\mathrm{CI}$. Compared with Carlsson et $\mathrm{al}^{6}{ }^{6}$ the level of depression in this population is not as high, and does not correlate with the degree of HI, which might depend on methodological differences. Whether the HADS should be considered as ordinal or interval data is a topic of discussion. In the present study, the sum of the HADS scores was treated as ordinal data because "not often" is not doubly as depressive as "sometimes."

Unlike previous studies, the present study could not show that age, cognitive performance or residual hearing can predict the $\mathrm{CI}$ outcome. We did not find a correlation between age and BPSR, age and cognitive performance, and age and HUI3 post$\mathrm{CI}$, which is in accordance with several studies, ${ }^{14,27,45,46}$ and, consequently, supports the indication of $\mathrm{CI}$ at all ages. The lack of significance between cognitive performance and SR/SR postCI may possibly be due to fact that the tests that estimate speech perception are not cognitively demanding enough to be decisive. Even though residual hearing cannot predict the $\mathrm{CI}$ outcome, it is worth noting that individuals with low SR pre-CI can achieve the highest gains in SR. The other background factors, such as etiology, operated side, and level of anxiety or depression, did not have any significance on the CI outcomes. The only predictor with high correlation to a high SR one year post-CI in the present study was the female gender. The role of gender needs to be explored more in depth in future studies.

There are only few published results regarding gender differences in the $\mathrm{CI}$ outcomes. Lenarz et $\mathrm{al},{ }^{19,25}$ found that men performed better than women in more complex listening situations such as in-noise speech tests, but found no differences in the monosyllabic test. ${ }^{25}$ In the present study, more women than men were implanted, at a lower age, and had less residual hearing with respect to a higher PTA (and a larger SD). As we could not observe a correlation between age or residual hearing with the hearing outcomes post- $\mathrm{CI}$, no association between the women's lower age and higher PTA pre-CI and the women's significantly better SR one year post-CI was found. Despite this, men scored higher and improved more in the HUI3 HU than women; in other words, men experienced more improvement in their hearing than women. It is a novel finding that women perform significantly better in SR. Bodmer et $\mathrm{al}^{27}$ did not find a correlation between gender and SR post-CI, but, unlike the present study, they retrospectively analyzed 444 adults (with an average age of 47 years and $45 \%$ of men) with pre- and postlingual HI. ${ }^{27}$ Women with profound $\mathrm{HI}$ tended to display lower HRQoL than men, ${ }^{4}$ a result that is in accordance with those of the present study. Men scored higher in the HUI3 OU pre- and one year post-CI. There seem to be some gender differences in CI outcomes that might be important to consider when dealing with $\mathrm{CI}$ users/CI candidates, and more research is needed to look further into the gender differences.

The strengths of the present study are the inclusion of the definition of HRQoL, the pre-CI assessment of cognitive ability, the monitoring with HADS, the one- and three-year follow-up, and the gender perspective. The shortcomings of the present study include the number of study subjects and the relative large variation in etiologies.

\section{Conclusion}

The results of the present study showed a significant benefit of $\mathrm{CI}$ in adults with postlingual $\mathrm{HI}$ regarding SR and HRQoL one year post-CI, but without mutual correlation. Three years post-CI, the SR and HUI3 OU were unchanged, whereas the HUI3 HU improved significantly. The present study also confirmed that the HUI3 can be used to assess HRQoL in a population of people with $\mathrm{CI}$, and that the HADS can be used to follow up on levels of depression and anxiety. In the present study, age, etiology, side of implantation, residual hearing, level of anxiety and depression and cognitive performance did not predict the $\mathrm{CI}$ outcome concerning SR and HRQoL, but the female gender did.

\section{Funding}

The present study was supported by the Swedish Research Council for health, Working Life and Welfare FAS dnr 2010-0761.

\section{Conflict of Interests}

The authors have no conflict of interests to declare.

\section{References}

1 Saunders JE, Rankin Z, Noonan KY. Otolaryngology and the Global Burden of Disease. Otolaryngol Clin North Am 2018;51(03):515-534

2 Sjöstedt C. Annual Report from the ENT-Quality Register in Sweden 2014. SVENSK ÖNH TIDSKRIFT. 2015(SA1/2015):10.

3 Dalton DS, Cruickshanks KJ, Klein BE, Klein R, Wiley TL, Nondahl DM. The impact of hearing loss on quality of life in older adults. Gerontologist 2003;43(05):661-668

4 Ringdahl A, Grimby A. Severe-profound hearing impairment and health-related quality of life among post-lingual deafened Swedish adults. Scand Audiol 2000;29(04):266-275

5 Li CM, Zhang X, Hoffman HJ, Cotch MF, Themann CL, Wilson MR. Hearing impairment associated with depression in US adults, National Health and Nutrition Examination Survey 2005-2010. JAMA Otolaryngol Head Neck Surg 2014;140(04):293-302

6 Carlsson PI, Hjaldahl J, Magnuson A, et al. Severe to profound hearing impairment: quality of life, psychosocial consequences and audiological rehabilitation. Disabil Rehabil 2015;37(20): 1849-1856

7 Genther DJ, Betz J, Pratt S, et al; Health, Aging and Body Composition Study. Association Between Hearing Impairment and Risk of Hospitalization in Older Adults. J Am Geriatr Soc 2015;63(06): 1146-1152

8 Feeny D, Huguet N, McFarland BH, Kaplan MS, Orpana H, Eckstrom E. Hearing, mobility, and pain predict mortality: a longitudinal population-based study. J Clin Epidemiol 2012;65(07):764-777

9 Bond M, Mealing S, Anderson R, et al. The effectiveness and costeffectiveness of cochlear implants for severe to profound deafness in children and adults: a systematic review and economic model. Health Technol Assess 2009;13(44):1-330

10 healthcare tSnbowa. The Swedish national board of well and healthcare, 20112011 [Available from: www.socialstyrelsen.se.

11 Damen GW, Beynon AJ, Krabbe PF, Mulder JJ, Mylanus EA. Cochlear implantation and quality of life in postlingually deaf adults: long-term follow-up. Otolaryngol Head Neck Surg 2007; 136(04):597-604 
12 Capretta NR, Moberly AC. Does quality of life depend on speech recognition performance for adult cochlear implant users? Laryngoscope 2016;126(03):699-706

13 Chung J, Chueng K, Shipp D, et al. Unilateral multi-channel cochlear implantation results in significant improvement in quality of life. Otol Neurotol 2012;33(04):566-571

14 Klop WM, Boermans PP, Ferrier MB, van den Hout WB, Stiggelbout AM, Frijns JH. Clinical relevance of quality of life outcome in cochlear implantation in postlingually deafened adults. Otol Neurotol 2008;29(05):615-621

15 Straatman LV, Huinck WJ, Langereis MC, Snik AF, Mulder JJ. Cochlear implantation in late-implanted prelingually deafened adults: changes in quality of life. Otol Neurotol 2014;35(02):253-259

16 Lassaletta L, Castro A, Bastarrica M, de Sarria MJ, Gavilan J. Quality of life in postlingually deaf patients following cochlear implantation. Eur Arch Otorhinolaryngol 2006;263(03):267-270

17 Hirschfelder A, Gräbel S, Olze H. The impact of cochlear implantation on quality of life: the role of audiologic performance and variables. Otolaryngol Head Neck Surg 2008;138(03):357-362

18 McRackan TR, Bauschard M, Hatch JL, et al. Meta-analysis of Cochlear Implantation Outcomes Evaluated With General Health-related Patient-reported Outcome Measures. Otol Neurotol. 2018;39(01):29-36

19 Lenarz M, Sönmez H, Joseph G, Büchner A, Lenarz T. Long-term performance of cochlear implants in postlingually deafened adults. Otolaryngol Head Neck Surg 2012;147(01):112-118

20 Ruffin CV, Tyler RS, Witt SA, Dunn CC, Gantz BJ, Rubinstein JT Long-term performance of Clarion 1.0 cochlear implant users. Laryngoscope 2007;117(07):1183-1190

21 Jolink C, Helleman HW, van Spronsen E, Ebbens FA, Ravesloot MJ, Dreschler WA. The long-term results of speech perception in elderly cochlear implant users. Cochlear Implants Int 2016;17(03):146-150

22 Hilly O, Hwang E, Smith L, et al. Cochlear implantation in elderly patients: stability of outcome over time. J Laryngol Otol 2016;130 (08):706-711

23 Holden LK, Finley CC, Firszt JB, et al. Factors affecting open-set word recognition in adults with cochlear implants. Ear Hear 2013; 34(03):342-360

24 Kraaijenga VJ, Smit AL, Stegeman I, Smilde JJ, van Zanten GA, Grolman W. Factors that influence outcomes in cochlear implantation in adults, based on patient-related characteristics - a retrospective study. Clin Otolaryngol 2016;41(05):585-592

25 Lenarz M, Sönmez H, Joseph G, Büchner A, Lenarz T. Effect of gender on the hearing performance of adult cochlear implant patients. Laryngoscope 2012;122(05):1126-1129

26 Green KM, Bhatt Y, Mawman DJ, et al. Predictors of audiological outcome following cochlear implantation in adults. Cochlear Implants Int 2007;8(01):1-11

27 Bodmer D, Shipp DB, Ostroff JM, et al. A comparison of postcochlear implantation speech scores in an adult population. Laryngoscope 2007;117(08):1408-1411

28 Shin MS, Song JJ, Han KH, et al. The effect of psychosocial factors on outcomes of cochlear implantation. Acta Otolaryngol 2015; 135(06):572-577
29 Liden G. Speech audiometry; an experimental and clinical study with Swedish language material. Acta Otolaryngol Suppl 1954;114:1-145

30 Descriptions for pure-tone audiograms. British Journal of audiology. 1988(22:2):123

31 Patrick DLEP. Health Status and Health Policy: Quality of life in Health Care Evaluation and Resource Allocation. New York: Oxford University Press; 1993:478

32 Horsman J, Furlong W, Feeny D, Torrance G. The Health Utilities Index (HUI): concepts, measurement properties and applications. Health Qual Life Outcomes 2003;1:54

33 Bjelland I, Dahl AA, Haug TT, Neckelmann D. The validity of the Hospital Anxiety and Depression Scale. An updated literature review. J Psychosom Res 2002;52(02):69-77

34 Zigmond AS, Snaith RP. The hospital anxiety and depression scale. Acta Psychiatr Scand 1983;67(06):361-370

35 Carlsson PI, Hall M, Lind KJ, Danermark B. Quality of life, psychosocial consequences, and audiological rehabilitation after sudden sensorineural hearing loss. Int J Audiol 2011;50(02):139-144

36 Studebaker GAA. A "rationalized" arcsine transform. J Speech Hear Res 1985;28(03):455-462

37 Yang Y, Longworth L, Brazier J. An assessment of validity and responsiveness of generic measures of health-related quality of life in hearing impairment. Qual Life Res 2013;22(10):2813-2828

38 Grutters JP, Joore MA, van der Horst F, Verschuure H, Dreschler WA, Anteunis LJ. Choosing between measures: comparison of EQ5D, HUI2 and HUI3 in persons with hearing complaints. Qual Life Res 2007;16(08):1439-1449

39 Ramakers GG, Smulders YE, van Zon A, et al. Agreement between health utility instruments in cochlear implantation. Clin Otolaryngol 2016;41(06):737-743

40 Drummond $M$. Introducing economic and quality of life measurements into clinical studies. Ann Med 2001;33(05):344-349

41 Lenarz T, James C, Cuda D, et al. European multi-centre study of the Nucleus Hybrid L24 cochlear implant. Int J Audiol 2013;52 (12):838-848

42 Arnoldner C, Lin VY, Bresler R, et al. Quality of life in cochlear implantees: comparing utility values obtained through the Medical Outcome Study Short-Form Survey-6D and the Health Utility Index Mark 3. Laryngoscope 2014;124(11):2586-2590

43 Karinen PJ, Sorri MJ, Välimaa TT, Huttunen KH, Löppönen HJ. Cochlear implant patients and quality of life. Scand Audiol Suppl 2001;52(52):48-50

44 Turunen-Taheri S, Skagerstrand Å, Hellström S, Carlsson PI. Patients with severe-to-profound hearing impairment and simultaneous severe vision impairment: a quality-of-life study. Acta Otolaryngol 2017;137(03):279-285

45 Francis HW, Yeagle JA, Thompson CB. Clinical and psychosocial risk factors of hearing outcome in older adults with cochlear implants. Laryngoscope 2015;125(03):695-702

46 Távora-Vieira D, Marino R, Acharya A, Rajan GP. The impact of cochlear implantation on speech understanding, subjective hearing performance, and tinnitus perception in patients with unilateral severe to profound hearing loss. Otol Neurotol 2015; 36(03):430-436 